\title{
An Improved Cutting Force Model in Micro-milling Considering the Comprehensive Effect of Tool Runout, Size Effect and Tool Wear
}

\section{Tongshun Liu}

Soochow University

Yayun Liu ( $\square$ liuyayun6688@163.com )

Shandong University

Kedong Zhang

Soochow University

\section{Research Article}

Keywords: Micro milling, Cutting force, Tool runout, Size effect, Tool wear

Posted Date: July 19th, 2021

DOl: https://doi.org/10.21203/rs.3.rs-719669/v1

License: (c) (1) This work is licensed under a Creative Commons Attribution 4.0 International License.

Read Full License

Version of Record: A version of this preprint was published at The International Journal of Advanced Manufacturing Technology on February 3rd, 2022. See the published version at https://doi.org/10.1007/s00170-022-08777-1. 


\title{
An improved cutting force model in micro-milling considering the comprehensive effect of tool runout, size effect and tool wear
}

\author{
Tongshun Liu; Yayun Liu ${ }^{\varpi}$; Kedong Zhang \\ School of Mechanical and Electric Engineering, Soochow University. Suzhou, 215021, Jiangsu, China. \\ Tongshun Liu, E-mail: tongshunliu@hotmail.com \\ ${ }^{\square}$ Corresponding author: Yayun Liu, E-mail: liuyayun6688@163.com
}

Kedong Zhang, E-mail: zhangkedong@suda.edu.cn

\begin{abstract}
Tool runout, cutting edge radius-size effect and tool wear have significant impacts on the cutting force of micro-milling. In order to predict the micro-milling force and the machining performance related to the cutting force, it is necessary to establish a cutting force model including tool runout, cutting edge radius and tool wear. In this study, an instantaneous uncut thickness (IUCT) model considering tool runout, a nonlinear shear/ploughing coefficient model including cutting-edge radius and a friction force coefficient model embedded with flank wear width, are constructed respectively. By integrating the IUCT, the nonlinear shear/ploughing coefficient and the friction force coefficient, a comprehensive micromilling force model including the tool runout, size effect and tool wear is derived. Experiment results show that the proposed comprehensive model is efficient to predict the micro milling force.
\end{abstract}

Key words: Micro milling; Cutting force; Tool runout; Size effect; Tool wear

\section{Introduction}

Micro-milling, with the high machining efficiency and the ability of cutting diverse materials, is viewed as one of the most promising technology for fabricating the micro-electromechanical devices[1]. The cutting force, which is related to many machining performances, such as the vibration[2], deflection[3], stability[4] and energy consumption[5,6], plays an extremely important role in micromilling. Constructing an accurate cutting force model is of great importance for understanding the micro milling process.

With the development of micro-milling technology, the mechanism of micro-milling force has been intensively investigated. Over the past decade, different factors such as tool runout [7], elastic recovery[8], tool wear[9], dead metal zone[10], edge radius size effect[11] and chip thickness accumulation[12], have been considered into the micro-milling force model. Among these factors, tool runout, edge radius size effect and tool wear have a particularly significant impact on micro milling force, and attract more attentions in the field of micro-milling research.

Due to the manufacturing and clamping errors, the tool runout is inevitable in the micro-milling process. As the feed speed per tooth in micro-milling is usually within a few microns, slight tool runout will significantly affect the uncut thickness (UCT) and the cutting force. Bao et al. [7] consider the UCT formed by the adjacent cutting teeth and built an analytic UCT model for micro-milling under tool runout. Li and Zhu[13] built a generic UCT model for flat micro end milling, in which the UCTs formed by all of the teeth are considered. Zhu et al. [14] extended the generic UCT model to ball end milling, and improved the force prediction accuracy in micro end ball milling.

Limited by the tool sharpening technology, the cutting edge is not absolutely sharp. The cutting-edge radius of the micro-milling tool is usually comparable to the uncut thickness. The comparability of the cutting-edge radius and the uncut thickness, viz. the edge radius size effect, leads to an obvious minimum uncut thickness (MUCT) phenomenon and ploughing effect[15], which greatly changes the micromilling force. Liu et al. [16]deduced that the ratio of the MUCT to the edge radius is a function of the effective flow stress and the shear strength. By assuming that the total ploughing force and the shear 
force at the MUCT point are equivalent, Son et al. [17] expressed the stagnant angle corresponding to the MUCT as a function of the friction angle. Based on the minimum cutting energy principle and the infinite stress principle[18], Malekian et al. [19]concluded that the stagnant angle equals to the friction angle.

Under the high rotation speed, the tiny-size micro-milling tool wears rapidly, resulting in a sharp increase in micro milling force. Bao et al.[20] built an experienced relationship between the tool wear and the amplitude of micro-milling force. Based on the friction stress distribution formular[21], Lu et al.[9] built a flank wear-included force model for Niki micro-milling. Compared to the flank wear, the effect of cutting-edge wear on the cutting force is much less studied. By assuming that both of the edge radius and the flank wear width increase with the deteriorating tool wear condition, Zhou et al. [22] attempted to build a cutting force model considering the edge wear and flank wear.

The works mentioned above have deeply investigated the individual effect of the tool runout, edge radius effect and tool wear on micro milling force. Besides, some other studies have explored the influence of the pairwise combination of the three factors on the cutting force of micro-milling. The combined effect of the tool wear and cutting-edge radius on the force was reported in study [22]. Jing et al. [8]considered the edge radius and runout, and built an analytic micro milling force model. Li et al.[23] adopted the spatial analytic geometry method to analysis the combined effect of the tool runout and wear the micro-milling force. Liu et al.[24] built a micro-milling force model including the tool runout and tool wear, and proposed a cutting force model-based tool wear monitoring method under varying tool runout. However, so far, to our best knowledge, no studies have considered the comprehensive effect of tool runout, cutting-edge radius and tool wear on the micro milling force. To bridge this gap, this study builds a mechanics micro milling force model considering the tool runout, cutting-edge radius and tool wear, and investigate the comprehensive effect of the three factors on the micro milling force.

The cutting force modeling process in this study is as follows. Firstly, the IUCT model including the tool runout is constructed. Then, a nonlinear shear/ploughing cutting coefficient model including the IUCT and the cutting-edge radius is derived, and the friction force coefficient in the flank wear region is represented as a function of the flank wear width. Finally, by integrating the IUCT, the shear/ploughing cutting coefficient and the friction force coefficient, a comprehensive micro-milling force model including tool runout, edge radius effect and the tool wear is constructed.

This paper evolves as follows. In section 2, the comprehensive micro milling force model is constructed. Section 3 proposes a genetic optimization-based model parameters calibration approach. In section 4, micro milling experiment is conducted to examine the efficiency of the proposed model. The paper is concluded in section 5 .

\section{The Improved Cutting Force Model for Micro-Milling}

The proposed model is shown in Fig. 1. The input layer of the model consists of the tool runout, cutting edge radius and the flank wear. The second layer is the middle variables including the IUCT, the shear-ploughing coefficient and the friction coefficient. The output layer is the theoretical micromilling force.

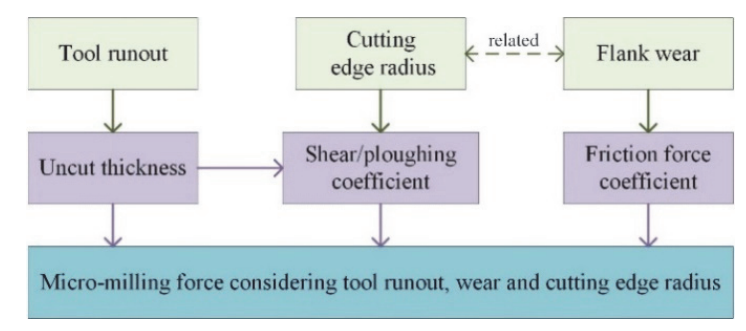

Fig.1 The flowchart of constructing the comprehensive micro-milling force model 
The comprehensive model in Fig.1 is:

$$
\begin{aligned}
& \mathrm{d} F_{c}=\left[\int_{0}^{h} K_{c, s p}\left(h^{\prime} \mid \lambda_{s}, r_{e}, \alpha\right) \cdot \mathrm{d} h^{\prime}+K_{c, v b}\left(V B \mid \lambda_{v}\right)\right] \mathrm{d} z \\
& \mathrm{~d} F_{r}=\left[\int_{0}^{h} K_{r, s p}\left(h^{\prime} \mid \lambda_{s}, r_{e}, \alpha\right) \cdot \mathrm{d} h^{\prime}+K_{r, v b}\left(V B \mid \lambda_{v}\right)\right] \mathrm{d} z
\end{aligned}
$$

Notation $\mathrm{d} F_{c}$ is the tangential force, $\mathrm{d} F_{r}$ is radial force, $\mathrm{d} z$ is the unit axial cutting depth. Notation $h$ is the instantaneous uncut thickness, which depends on the tool runout. Notation $V B$ is the flank wear width, $r_{e}$ is the cutting-edge radius related to the flank wear width, $\alpha$ is the rake angle. Notation $K_{c, s p}$ is the shear-ploughing coefficient in tangential direction, $K_{r, s p}$ is the shear-ploughing coefficient in radial direction. The shear-ploughing coefficient varies with the IUCT. If the partial IUCT $h^{\prime}$ is greater than the minimum uncut thickness $h_{m}$, the shear-ploughing coefficient represents the cutting force resulting from the shear effect (Fig.2a). Otherwise, the shear-ploughing coefficient corresponds to the ploughing force (Fig.2b). Notation $K_{c, v b}$ is the tangential friction force coefficient in flank wear region, $K_{r, v b}$ is the radial friction force coefficient. Mechanical parameter set $\lambda_{s}=\left\{\tau_{s}, \beta_{s}, \tau_{m}, \sigma_{m}\right\}$ includes the shear stress $\tau_{s}$, friction angle $\beta_{s}$, normal cutting stress $\sigma_{m}$ and the tangential cutting stress $\tau_{m}$ in ploughing region. Mechanical parameter set $\lambda_{v}=\left\{V B^{*}, \tau_{v}, \sigma_{v}\right\}$ consists of the normal friction stress $\sigma_{v}$, tangential friction stress $\tau_{v}$ and the width of elastic contact region $V B^{*}$.

(a)

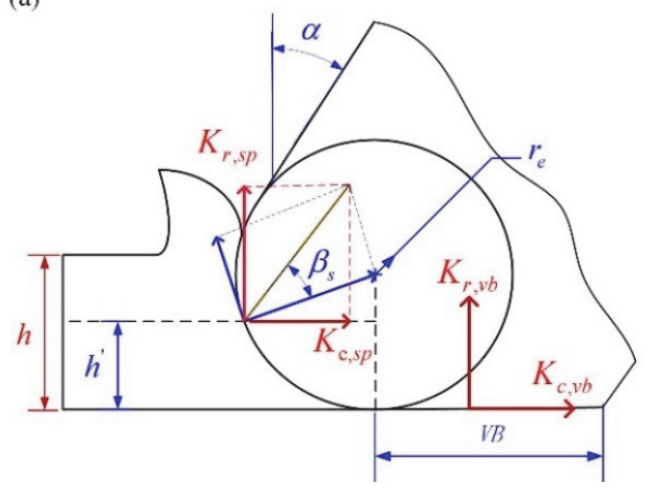

(b)

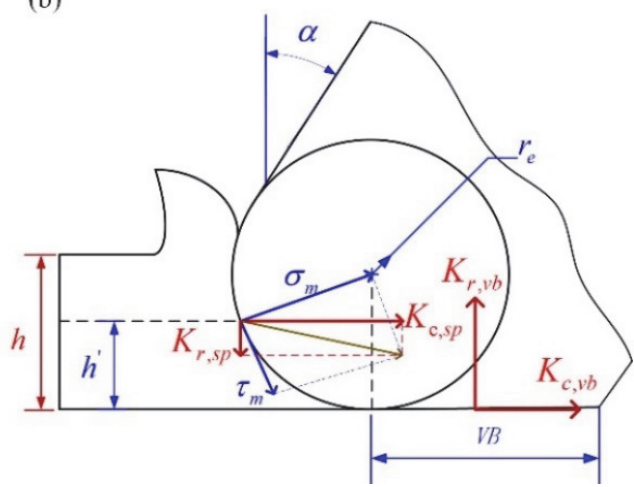

Fig.2 The cutting force model: (a) shear effect with $h^{\prime}>h_{m}$;(b) ploughing effect with $h^{\prime}<h_{m}$

The construction of the IUCT model considering tool runout, the shear/ploughing coefficient model considering cutting edge radius and the friction force coefficient model with flank wear width are elaborated in the fowling three subsections.

\subsection{Uncut Thickness Model considering Tool Runout}

By changing the equivalent tool radius and the angle between the radius, axial tool runout makes the trochoidal trajectory and the IUCT of each tooth change. Because the axial cutting depth is much smaller than the length of tool, the radial tool runout could be regarded as the translation of the cutting part at the bottom of the micro-milling tool, and thus the tool runout could be represented by the length $r_{o}$ and the angle $\gamma_{o}$ of the translation vector. According to studies[13,24], the IUCT of the $k-t h$ equivalent radius at cutting depth $z$ at reference position angle $\phi$ could be written as: 


$$
h_{k, z}(\phi)=\max \left\{\min _{m}\left[R_{k, z}-R_{m, z}+f_{z} \sin \left(\phi_{k}^{z}\right) \frac{M \cdot \Delta \theta_{m, k}^{z}}{2 \pi}\right], 0\right\}
$$

Notation $R_{k, z}$ is the $k$-th equivalent radius at cutting depth $z, \Delta \theta_{m, k}^{z}$ is the angle that the $k-t h$ equivalent radius clockwise leads the $m-t h$ equivalent radius at depth $z$. $\phi_{k}^{z}$ is the rotation angle of the $k$-th equivalent radius at depth $z, f_{z}$ is the feed per tooth. The detailed calculation process of determining the equivalent radius $R_{k, z}$ and the equivalent angles $\Delta \theta_{m, k}^{z}$ by the tool runout parameters $\left(r_{o}, \gamma_{o}\right)$ could refer to study [24].

\subsection{Shear/Ploughing Coefficient Model considering Cutting Edge Radius}

The comparability of the IUCT and cutting-edge radius, viz. the tool edge radius size effect, lead to the minimum uncut thickness and nonlinear IUCT-varying shear/ploughing coefficient. In this study, an analytic MUCT model is derived by assuming the normal ploughing force and the normal shear force are equivalent at the MUCT point (Fig.3). The assumption could be written as:

$$
r_{e} \sigma_{m} \mathrm{~d} \theta \mathrm{d} z=\frac{\tau_{s} \cos \left(\beta_{s}\right)}{\sin ^{2}\left(\frac{\theta_{s}-\beta_{s}}{2}\right)} \mathrm{d} h \mathrm{~d} z
$$

The left of Eq.(4) is the norm ploughing force $\mathrm{d} F_{p, n}$ in Fig.3, the right is the normal shear force $\mathrm{d} F_{s, n}$ under the minimum energy principle[18], $\theta_{s}$ is the stagnant angle corresponding to MUCT. By solving Eq. (4) , the analytic stagnant angle is derived as:

$$
\theta_{s}=\pi-\arcsin \left\{\frac{\sigma_{m}}{\sqrt{4 \tau_{s}^{2} \cos ^{4} \beta_{s}+\left(\tau_{s} \sin 2 \beta_{s}+\sigma_{m}\right)^{2}}}\right\}-\arctan \left\{\tan \beta_{s}+\frac{\sigma_{m}}{2 \tau_{s} \cos ^{2} \beta_{s}}\right\}+\beta_{s}
$$

The MUCT value is:

$$
h_{\mathrm{m}}=r_{e}\left(1-\cos \theta_{s}\right)
$$

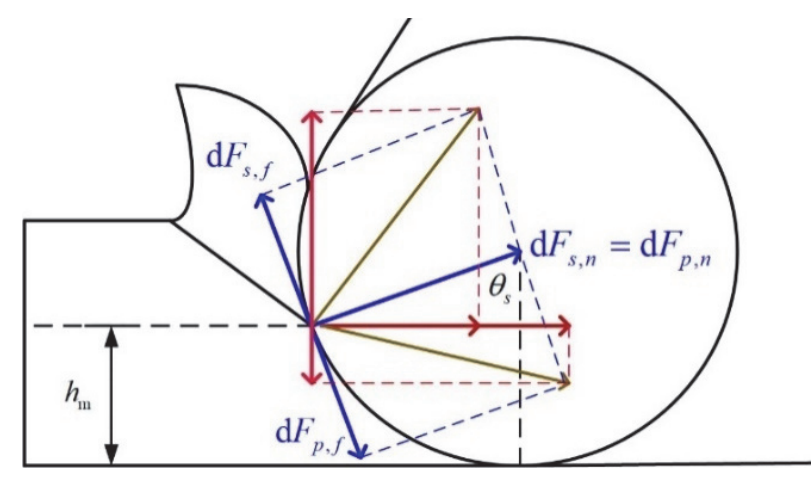

Fig.3 The MUCT model based on the assumption that the normal ploughing force and the normal shear force are equivalent at the MUCT point

The angle of the intersection point of rake face and round nose is $\theta_{\lim }$, and the corresponding UCT is $h_{\lim }=r_{e}-r_{e} \cos \theta_{\lim }$. According to the UCT value, the whole cutting region could be divided into three parts: the ploughing region with $h<h_{\mathrm{m}}$, the shear region with UCT-varying shear force coefficient ( $h_{\mathrm{m}} \leq h<h_{\text {lim }}$ ) and the part with constant shear force coefficient ( $h \geq h_{\text {lim }}$ ). The shear/ploughing coefficient in the three different part is: 


$$
K_{c, s p}\left(h \mid \lambda_{s}, r_{e}, \alpha\right)=\left\{\begin{array}{cr}
\frac{\tau_{s} \sin \left(\theta_{\lim }-\beta_{s}\right)}{\sin ^{2}\left(\frac{\theta_{\lim }-\beta_{s}}{2}\right)} & h \geq h_{\mathrm{lim}} \\
\frac{\tau_{s} \sin \left(\theta-\beta_{s}\right)}{\sin ^{2}\left(\frac{\theta-\beta_{s}}{2}\right)} & h_{\mathrm{m}} \leq h<h_{\mathrm{lim}} \\
\sigma_{m}+\tau_{m} \cot \theta & 0 \leq h<h_{\mathrm{m}}
\end{array}\right\}
$$

\subsection{Friction Force Coefficient in Flank Wear Region}

The relationship between the flank tool wear and the friction force coefficient has been clearly revealed in the existed studies. According to the friction stress distribution formular, the relationship between the friction force coefficient and the flank wear could be written as:

$$
\begin{array}{cc}
K_{c, v b}\left(V B \mid \lambda_{v}\right)= \begin{cases}\frac{\tau_{v}}{3} \cdot V B & V B<V B^{*} \\
\tau_{v}\left(V B-\frac{2}{3} V B^{*}\right) & V B \geq V B^{*}\end{cases} \\
K_{c, v b}\left(V B \mid \lambda_{v}\right)= \begin{cases}\frac{\sigma_{v}}{3} \cdot V B & V B<V B^{*} \\
\sigma_{v}\left(V B-\frac{2}{3} V B^{*}\right) & V B \geq V B^{*}\end{cases}
\end{array}
$$

Many studies showed that the cutting-edge radius varies with the flank wear width. However, due to the uncertain build up edge and micro chipping that affect the effective cutting-edge radius, it is difficult to build a deterministic analytic model to represent the relationship between the edge radius and the flank tool wear width. To revel the dependency of the cutting-edge radius on the flank wear width, in the experimental validation part, empirical relationship between the calibrated edge radius and the measured flank wear width is analyzed by statistical correlation analysis method.

\section{Calibration of the Model Parameters}

Genetic optimization algorithm is adopted to calibrate the model parameters. Besides the two unknown mechanical parameter sets $\lambda_{s}$ and $\lambda_{v}$, the tool runout and the efficient edge radius are also calibrated via the genetic optimization algorithm. Practically, the static tool runout could be directly measured by optic measurements. However, the optic measurement-based method is incompetent to measure the dynamic rotation-speed-dependent runout in cutting process. Due to the build up edge and microchipping, it is also difficult to directly measure the effective cutting-edge radius by optical microscope or atomic force microscope. Therefore, in this study, the dynamic tool runout and the effective edge radius are also calibrated via the genetic optimization algorithm. The flank wear band is regular and the flank wear width 
could be directly measured by the optical microscope. In this study, the flank wear width is measure by Olympus Toolmakers microscope during the recess of tool holder.

Including the mechanical parameter sets $\lambda_{s}$ and $\lambda_{v}$, tool runout parameters, effective cutting-edge radius, there are 12 parameters need to be calibrated. The purpose of the optimization-based calibration is to find out the 12 optimum parameters, such that the gap between the theoretical force and the measured force is smallest. The measured forces in feed and normal directions are utilized to calibrate the parameters of the proposed model. In order to reduce the computation cost of the calibration process, instead of jointly optimizing the 12 parameters, the 12 parameters to be calibrated are optimized by three steps. Firstly, the cutting force signal, generated by the fresh tool with known edge radius and flank wear width, is adopted to calibrate the machinal parameters $\lambda_{s}$, and the parameter set $\lambda_{s}$ is set as a shared input of the subsequent calibration processes with worn tool. Then, with the sharing mechanical parameters $\lambda_{s}$, the friction force coefficient is calibrated under the worn tool. Finally, the parameters set $\lambda_{v}$ that reflects the relationship between the flank wear and the friction force coefficient, is calibrated with the calibrated friction force coefficients and the measured flank wear widths. The parameters need to be calibrated are listed in Table 1. The stepwise calibration process is shown in Fig.4.

Table 1

Parameters to be calibrated

\begin{tabular}{|c|c|c|c|}
\hline & meter to be calibrated & Notation & Unit \\
\hline \multirow{4}{*}{$\begin{array}{c}\text { Calibrated with } \\
\text { fresh tool }\end{array}$} & Friction angle & $\beta_{s}$ & $\mathrm{rad}$ \\
\hline & normal cutting stress & $\sigma_{m}$ & $N / \mu m^{2}$ \\
\hline & tangential cutting stress & $\tau_{m}$ & $N / \mu m^{2}$ \\
\hline & Shear stress & $\tau_{s}$ & $N / \mu m^{2}$ \\
\hline \multirow{9}{*}{$\begin{array}{c}\text { Calibrated with } \\
\text { worn tool }\end{array}$} & Cutting edge radius & $r_{e}$ & $\mu m$ \\
\hline & Length of tool runout & $r_{o}$ & $\mu m$ \\
\hline & Angle of tool runout & $\gamma_{o}$ & rad \\
\hline & tangential friction force coefficient & $K_{c, v b}$ & $N / \mu m$ \\
\hline & & & \\
\hline & radial friction force coefficient & $K_{r, v b}$ & $N / \mu m$ \\
\hline & tangential friction stress & $\tau_{v}$ & $N / \mu m^{2}$ \\
\hline & radial friction stress & $\sigma_{v}$ & $N / \mu m^{2}$ \\
\hline & width of elastic contact region & $V B^{*}$ & $\mu m$ \\
\hline
\end{tabular}




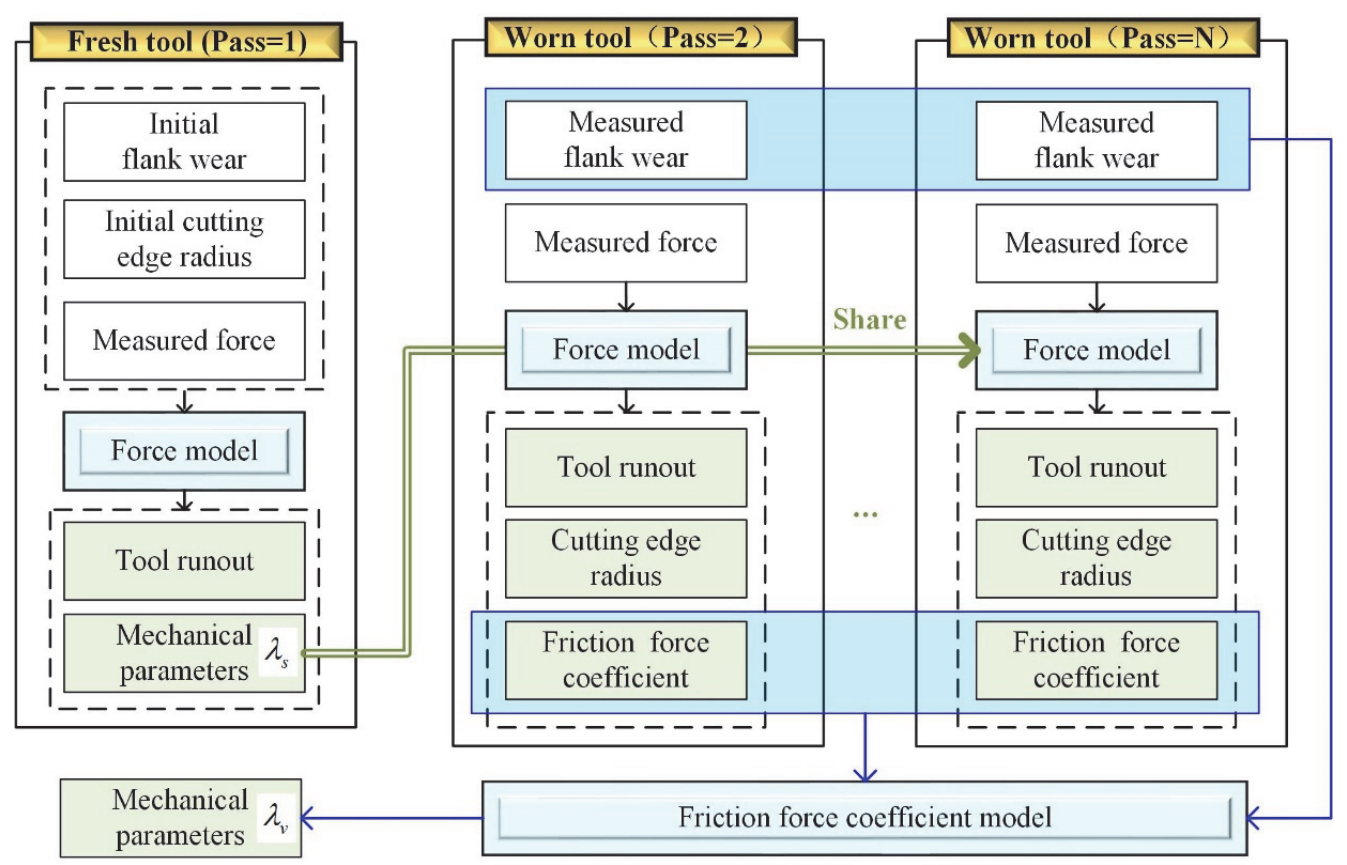

Fig.4 The parameters calibration process

\section{Experimental Validation}

\subsection{Experimental setup}

Micro slot milling is conducted to validate the proposed comprehensive micro-milling force model. The machine used in the experiments is MIKRON HSM600U vertical milling machine. The tool is CS2008-0200. Steel T4 is used as work-piece material. The cutting force is measured with a Kistler9109AA2 3-channel dynamometer. The sampling rate is $24 \mathrm{kHz}$. The flank wear width is measured by Olympus Toolmakers. There are 10 cutting passes. In each cutting pass, a 3-cm-long slot is machined. The cutting parameters used in this study are listed in Table 2. The geometric parameters of the fresh tool are listed in Table 3.

Table 2

Cutting parameters used in this study

\begin{tabular}{ccccc}
\hline Spindle speed & Axial cutting depth & Cutting speed & Feed speed & Feed per tooth \\
\hline $18000 \mathrm{rpm}$ & $80 \mu \mathrm{m}$ & $45.24 \mathrm{~m} / \mathrm{min}$ & $144 \mathrm{~mm} / \mathrm{min}$ & $4 \mu \mathrm{m}$ \\
\hline
\end{tabular}

Table 3

Geometric parameters of the micro-milling tool

\begin{tabular}{cccccc}
\hline $\begin{array}{c}\text { Tooth } \\
\text { number }\end{array}$ & $\begin{array}{c}\text { Tool } \\
\text { diameter }\end{array}$ & $\begin{array}{c}\text { Rake } \\
\text { angle }\end{array}$ & $\begin{array}{c}\text { Clearance } \\
\text { angle }\end{array}$ & $\begin{array}{c}\text { Initial cutting } \\
\text { edge radius }\end{array}$ & $\begin{array}{c}\text { Initial flank } \\
\text { wear width }\end{array}$ \\
\hline 2 & $0.5 \mathrm{~mm}$ & $0^{\circ}$ & $6^{\circ}$ & $2 \mu m$ & $0 \mu m$ \\
\hline
\end{tabular}

\subsection{Parameter calibration results}

The cutting force signal acquired during the first cutting pass is adopted to calibrate the four mechanical parameters: the shear stress, friction angle in shear region, normal and tangential cutting stresses in 
ploughing region. It is assumed that the tool at the first cutting pass is fresh. The tool edge radius at the first cutting pass is the initial cutting-edge radius $(2 \mu \mathrm{m})$, and the flank wear width at the first cutting pass is $0 \mu \mathrm{m}$. By taking the initial cutting-edge radius and the flank wear width into the proposed cutting force model and comparing the theoretical force and the measured cutting force, the four mechanical parameters along with the runout parameters are calibrated. The calibration results are listed in Table 4. Taking the calibrated shear stress, friction angle in shear region and the normal cutting stress in ploughing region into the MUCT model proposed in section 2.2, the ratio of the MUCT value to the cutting-edge radius is calculated as 0.3537 . This result is consistent to the findings in most of the studies [25-27] which indicate the ratio is in the range of $[0.2,0.4]$.

Table 4

Calibration results of cutting pass 1

\begin{tabular}{cccccc}
\hline$\beta_{s}$ & $\sigma_{m}$ & $\tau_{m}$ & $\tau_{s}$ & $r_{o}$ & $\gamma_{o}$ \\
\hline 0.557 & 0.027 & 0.026 & 0.001 & 1.022 & 2.046 \\
\hline
\end{tabular}

The mechanical parameters $\lambda_{s}=\left\{\tau_{s}, \beta_{s}, \tau_{m}, \sigma_{m}\right\}$ calibrated at the first cutting pass are shared with the subsequent cutting passes. At the following cutting passes, the cutting-edge radius and the flank wear width vary with the tool wear condition. The flank wear width is directly measured. The effective cuttingedge radius, the flank wear width-dependent friction force coefficients and the runout parameters are jointly calibrated via the calibration algorithm proposed in section 3 . The calibrated results are shown in Table 5. As the tool is re-clamped at the beginning of each cutting pass, the runout parameter cannot keep constant for different cutting passes. This could be noticed from Table 5. The varying process of the flank wear width and the effective cutting-edge radius is shown in Fig.5. It clearly shows that the cutting-edge radius increases as the flank wear width increases. The correlation coefficient of the cuttingedge radius and the flank wear width is calculated as 0.8842 , implying that the effective cutting-edge radius highly depends on the flank wear width.

\section{Table 5}

Calibration results of all cutting passes

\begin{tabular}{ccccccc}
\hline Pass & $r_{e}$ & $r_{o}$ & $\gamma_{o}$ & $K_{c, v b}$ & $K_{r, v b}$ & $V B$ \\
\hline 1 & 0 & 1.022 & 2.046 & 0 & 0 & 0 \\
2 & 3.653 & 2.022 & 1.668 & 0.005 & 0.003 & 14 \\
3 & 4.184 & 2.140 & 1.715 & 0.012 & 0.005 & 15 \\
4 & 3.991 & 1.197 & 1.344 & 0.011 & 0.01 & 20 \\
5 & 4.218 & 2.823 & 1.694 & 0.012 & 0.01 & 22.5 \\
6 & 3.717 & 2.717 & 1.664 & 0.02 & 0.009 & 24.5 \\
7 & 4.482 & 0.372 & 0.907 & 0.015 & 0.01 & 27 \\
8 & 4.275 & 0.595 & 0.864 & 0.016 & 0.019 & 29 \\
9 & 4.734 & 0.929 & 1,306 & 0.021 & 0.011 & 33.5 \\
10 & 5.618 & 0.703 & 1.221 & 0.035 & 0.015 & 35 \\
\hline
\end{tabular}



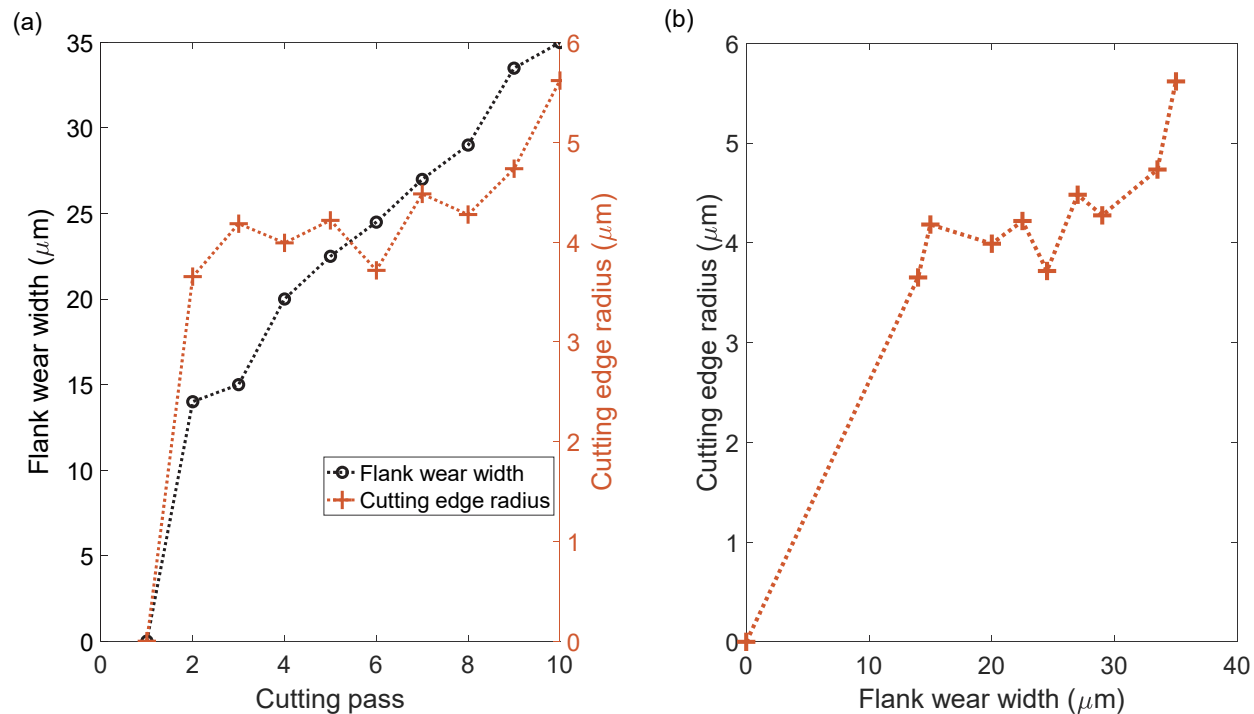

Fig.5 The flank wear and the cutting-edge wear: (a) flank wear width and cutting-edge radius VS cutting pass; (b) cutting edge radius VS flank wear width.

The calibrated friction force coefficients and the measured flank wear width are utilized to calibrate the tangential friction stress, radius friction stress and the constant width of elastic contact region. The calibrated friction force coefficients are shown in Fig.6. It shows that, the growth curve of the friction force coefficient could be approximately represented by a polyline with the width of elastic contact region as the turning point. To obtain the mechanical parameters, the calibrated friction force coefficients are fitted by the polylines defined in Eq. (9)-(10). The constant width of elastic contact region is calibrated as $V B^{*}=18.678 \mu \mathrm{m}$. The friction force stresses associated with the slop of the fitting polyline are calibrated as $\sigma_{v}=0.125 * 10^{-2} \mathrm{~N} / \mu \mathrm{m}^{2}, \tau_{v}=0.076 * 10^{-2} \mathrm{~N} / \mu \mathrm{m}^{2}$. Comparing the calibrated shear stress, cutting stress in ploughing region and the friction stress in flank wear region, it could be found that the cutting stress in ploughing is much bigger than the other two stresses. This implies that the micro-milling force is most concentrated in the ploughing region.

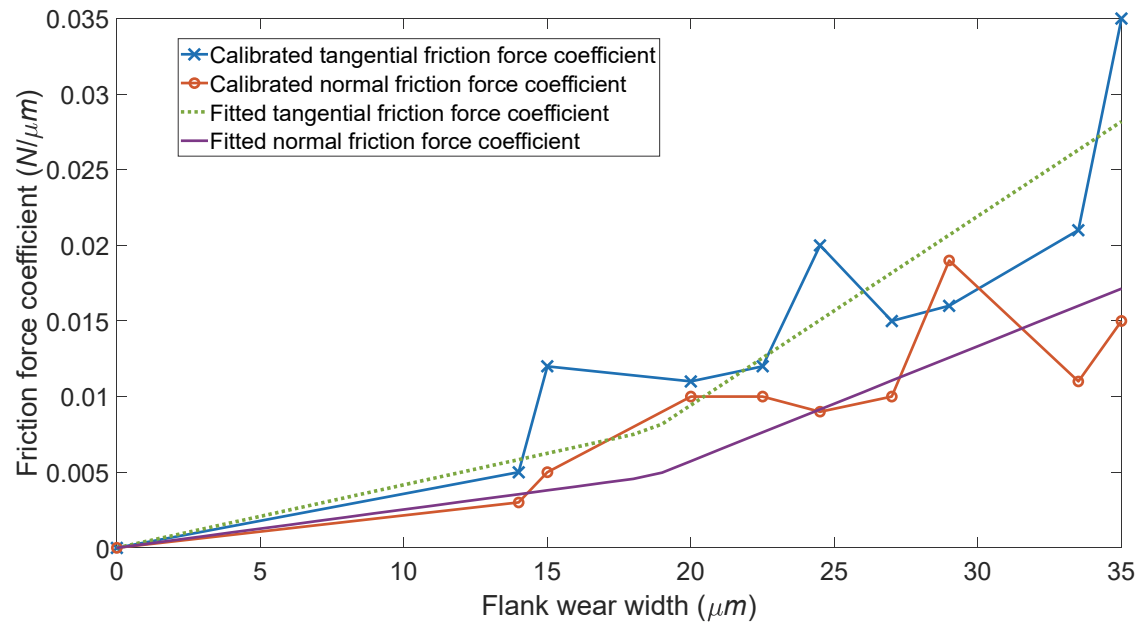

Fig.6 The relationship between the friction force coefficient and the flank wear width. 


\subsection{Micro milling force prediction results}

The cutting forces at the 10 passes are predicted via the proposed comprehensive model. The residual force is defined as the predicted force minus to the measured force. The estimated error is defined as the ratio of the second norm of the residual force to the second norm of the measured force. The predicted error is listed in Table 6. It shows that the proposed comprehensive model is accurate to predict the micro-milling force.

Table 6

Prediction error

\begin{tabular}{ccccccccccc}
\hline Pass & 1 & 2 & 3 & 4 & 5 & 6 & 7 & 8 & 9 & 10 \\
\hline Error $(\%)$ & 21.20 & 17.09 & 16.30 & 18.99 & 24.80 & 28.84 & 13.75 & 24.03 & 22.29 & 23.93 \\
\hline
\end{tabular}

Three conventional cutting force models are also utilized to predict the micro milling force in this study. Different from the proposed comprehensive model, the three conventional models only consider two factors. The first conventional model includes tool runout and cutting-edge radius. The second model considers tool runout and tool wear. The third one considers the cutting-edge radius and tool wear. Table 7 lists the prediction results of the three conventional models. It could be found that the proposed comprehensive model is more accurate than the three traditional models. This could also be concluded from Fig.7. Table 7 shows that, the model without considering the cutting-edge radius has a much higher prediction error than the other three models. This implies the cutting-edge radius has the most significant effect on the micro-milling force.

(a)

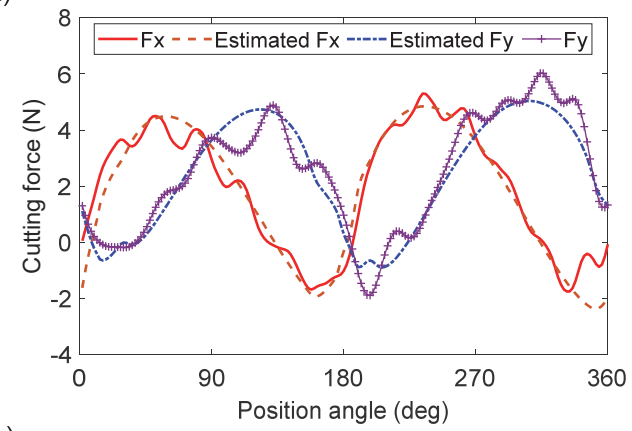

(c)

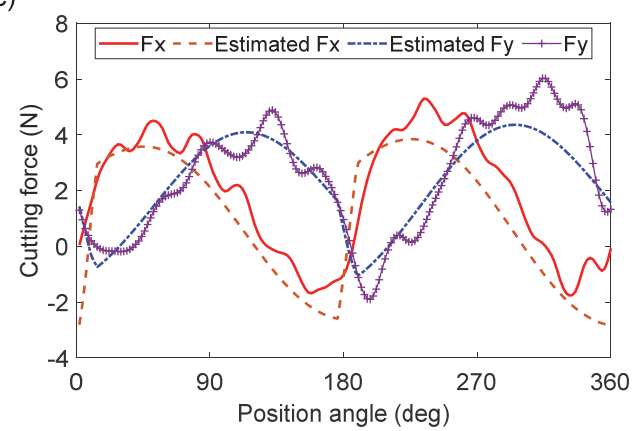

(b)

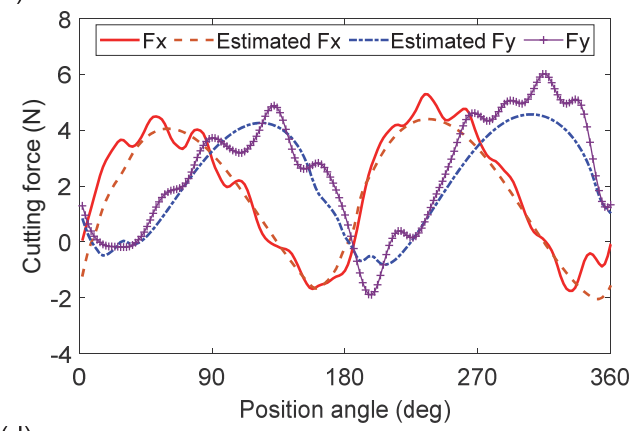

(d)

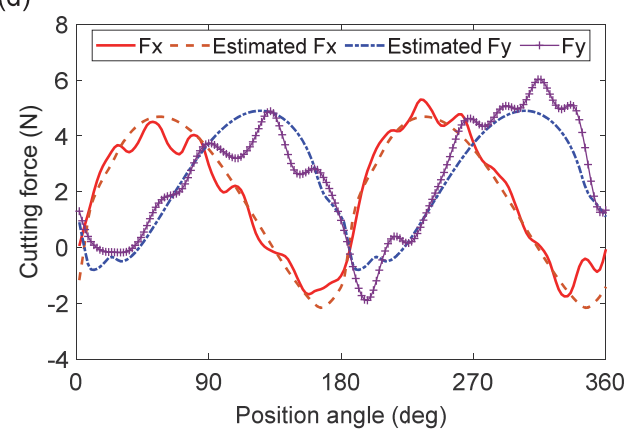

Fig.7 Cutting force prediction results at cutting pass 2 (a) Comprehensive model including tool runout, cuttingedge radius and tool wear; (b) Tool Runout \& Cutting-edge radius; (c) Tool Runout \& Tool wear; (d) Cutting-edge radius $\&$ Tool wear. 
Table 7

Comparison between different models

\begin{tabular}{cc}
\hline Model & Prediction error (\%) \\
\hline Tool Runout \& Cutting-edge radius & 24.59 \\
Tool Runout \& Tool wear & 31.03 \\
Cutting-edge radius \& Tool wear & 23.75 \\
Tool Runout \& Cutting-edge radius \& Tool wear & 17.09 \\
\hline
\end{tabular}

\section{Conclusion}

In order to accurately predict the micro-milling force, this study construct a micro-milling fore model considering the comprehensive effect of the tool runout, cutting edge radius and tool wear. The IUCT model inducing tool runout, nonlinear shear/ploughing coefficient model considering tool weardependent cutting-edge radius and the friction force coefficient function embedded with the flank wear are separately constructed. By integrating the IUCT, shear/ploughing coefficient and the friction force coefficient into the mechanism milling force model, a comprehensive micro-milling force model considering the tool runout, cutting edge radius and tool wear is derived. A genetic optimization-based stepwise calibration method is proposed to calibrate the parameters of the model. Experimental results show that the proposed model is efficient to predict the micro-milling force under varying tool runout, cutting edge radius and tool wear condition. Some conclusions are as follows.

1) Including tool runout, cutting edge radius and tool wear, the proposed comprehensive model is more accurate than the conventional models.

2) The cutting-edge radius increases as the flank wear width increases. The effective cutting-edge radius could be utilized to indicate the tool wear condition of micro milling.

3) The cutting stress in ploughing region is much higher than the shear stress and the friction stress in the flank wear region. The micro-milling force is most concentrated in the ploughing region.

4) Among the tool runout, cutting edge radius and tool wear, the cutting-edge radius has the most significant impact on micro-milling force.

\section{Acknowledgments}

The authors would like to thank the Lab of Precision Manufacturing, Institute of Advanced Manufacturing Technology, Chinese Academy of Sciences, for providing the raw experimental data.

\section{Declarations}

Funding. This work is supported by the National Natural Science Foundation of China (Grant No. 51905360) and the fellowship of China Postdoctoral Science Foundation (2020M681699).

Conflicts of interest/Competing interests. The authors have no conflicts of interest to declare that are relevant to the content of this article.

Availability of data and material. Not applicable.

Code availability. Not applicable.

Ethics approval. This paper does not contain any studies with human participants or animals performed by any of the authors.

Consent to participate. All of the authors consent to participate.

Consent for publication. All of the authors consent for publication.

Authors' contributions. Tongshun Liu constructed the theoretical model and wrote the manuscript. Yayun Liu designed and directed the project. Kedong Zhang analyzed the data. 


\section{Reference}

[1] Chen N, Li H N, Wu J, Li Z, Li L, Liu G, He N (2020). Advances in micro milling: From tool fabrication to process outcomes. Int J Mach Tools Manuf:103670

[2] Mustapha KB, Zhong ZW (2013) A hybrid analytical model for the transverse vibration response of a micro-end mill. Mech Syst Signal Process 34(1-2):321-339

[3] Jia Z, Lu X, Gu H, Ruan F, Liang S Y (2021) Deflection prediction of micro-milling Inconel 718 thin-walled parts. J Mater Process Tech 291: 117003

[4] Singh KK, Kartik V, Singh R (2018) Stability modeling with dynamic run-out in high speed micromilling ofTi6A14V. Int J Mech Sci 150:677-690

[5] Zhang X, Yu T, Dai Y, Qu S, Zhao J (2020) Energy consumption considering tool wear and optimization of cutting parameters in micro milling process. Int J Mech Sci 178: 105628

[6] Ray D, Puri AB, Naga H, Saurav H (2020) Analysis on specific cutting energy in micro milling of bulk metallic glass. Int J Adv Manuf 108(1-2), 245-261

[7] Bao WY, Tansel IN (2000) Modeling micro-end-milling operations, Part II: Tool run-out. Int J Mach Tools Manuf 40(15): 2175-2192

[8] Jing X, Lv R, Chen Y, Tian Y, Li H (2020) Modelling and experimental analysis of the effects of run out, minimum chip thickness and elastic recovery on the cutting force in micro-end-milling. Int J Mech Sci 176:105540

[9] Lu XH, Wang FR, Jia ZY, Si LK, Zhang C, Liang SY (2017) A modified analytical cutting force prediction model under the tool flank wear effect in micro-milling nickel-based superalloy. Int $\mathbf{J}$ Adv Manuf 91:3709-3716

[10] Wan M, Wen DY, Ma YC, Zhang WH (2019) On material separation and cutting force prediction in micro milling through involving the effect of dead metal zone. Int J Mach Tools Manuf 146: 103452

[11] Lai XM, Li HT, Li CF, Lin ZQ, Ni J (2008) Modelling and analysis of micro scale milling considering size effect, micro cutter edge radius and minimum chip thickness. Int $\mathrm{J}$ Mach Tools Manuf 48: 1-14

[12] Wojciechowski S, Matuszak M, Powałka B, Madajewski M, Maruda RW, Krolczyk GM (2019) Prediction of cutting forces during micro end milling considering chip thickness accumulation. Int J Mach Tools Manuf 147:103466

[13] Li K, Zhu K, Mei T (2016) A generic instantaneous undeformed chip thickness model for the cutting force modeling in micromilling. Int J Mach Tool Manu 105:23-31

[14] Zhu KP, Zhang Y (2017) Modeling of the instantaneous milling force per tooth with tool run-out effect in high speed ball-end milling. Int J Mach Tools Manuf 118:37-48

[15] Liu Z, Shi Z, Wan Y (2013) Definition and determination of the minimum uncut chip thickness of microcutting. Int J Adv Manuf 69(5): 1219-1232.

[16] Liu X, DeVor RE, Kapoor SG (2006) An analytical model for the prediction of minimum chip thickness in micromachining. J MANUF SCI E-T ASME 128(2): 474-481.

[17] Son SM, Lim HS, Ahn JH (2005) Effects of the friction coefficient on the minimum cutting thickness in micro cutting. Int J Mach Tools Manuf 45(4-5): 529-535.

[18] Altintas Y, Manufacturing automation: metal cutting mechanics, machine tool variations, and cnc design. 2nd ed. New York, USA: Cambridge University Press. 2012.

[19] Malekian M, Mostofa MG, Park SS, Jun MBG. (2012). Modeling of minimum uncut chip thickness in micro machining of aluminum. J Mater Process Tech 212(3): 553-559 
[20] BaoWY, Tansel IN (2000) Modeling micro-end-milling operations. Part III: influence of tool wear. Int J Mach Tools Manuf 40:2193-2211

[21] Hou YF, Zhang DH, Wu BH, Luo M(2015) Milling force modeling of worn tool and tool flank wear recognition in end milling. IEEE/ASME Trans Mechatron 20(3):1024-1035

[22] Zhou L, Deng B, Peng F, Yang M, Yan R (2020) Semi-analytic modelling of cutting forces in micro ball-end milling of NAK80 steel with wear-varying cutting edge and associated nonlinear process characteristics. Int J Mech Sci 169: 105343

[23] Li GC, Li S, Zhu KP (2020) Micro-milling force modeling with tool wear and runout effect by spatial analytic geometry. Int J Adv Manuf 107(1):631-643

[24] Liu TS, Zhu KP, Wang G (2020) Micro-milling tool wear monitoring under variable cutting parameters and runout using fast cutting force coefficient identification method. Int J Adv Manuf Technol 111: 3175-3188 (2020)

[25] Oliveira FB, Rodrigues AR, Coelho RT, Souza AF (2015) Size effect and minimum chip thickness in micromilling. Int J Mach Tools Manuf 89:39-54

[26] Kang IS, Kim JS, Seo YW (2011) Investigation of cutting force behaviour considering the effect of cutting edge radius in the micro-scale milling of AISI 1045 steel. Proceedings of the institution of mechanical engineers, Part B: Journal of Engineering Manufacture 225(2): 163-171

[27] Zong WJ, Huang YH, Zhang YL, Sun T (2014) Conservation law of surface roughness in single point diamond turning. Int J Mach Tools Manuf 84:58-63 